\title{
High-stable standard samples of mass in the nano-gram range
}

\author{
I.F.Mikhailov, A.A.Baturin, Ye.A.Bugaev, \\ A.I.Mikhailov, S.S.Borisova
}

\author{
National Technical University "Kharkiv Polytechnical Institute", \\ 21 Frunze Str., 61002 Kharkov, Ukraine
}

Received December 27, 2012

\begin{abstract}
High-stable mass standards prepared as magnetron sputtered super-smooth metal layers deposited on single crystal substrates were attested. The thin film standards were found to meet the requirements to government standards: they are homogeneous, long-lived, and can be attested by several independent methods. Using the standards, the measurement accuracy is provided not worse than $1 \mathrm{ng}$ in the range from 1 to $17 \mathrm{ng}$, and not worse than $8 \mathrm{ng}$ in the range from 17 to $3800 \mathrm{ng}$.
\end{abstract}

Исследованы высокостабильные эталоны масс, полученные методом магнетронного осаждения сверхгладких слоев металлов на монокристаллические подложки. Тонкопленочные эталоны отвечают требованиям, предъявляемым к государственным стандартным образцам: однородны, стабильны во времени и допускают аттестацию несколькими независимыми методами. Обеспечена точность измерений массы в диапазоне от 1 до 17 нг не хуже 1 нг, а в диапазоне от 17 до 3800 нг не хуже 8 нг.

\section{Introduction}

Development of nanotechnology, extrapure materials physics and other scientific fields demands quantitatively measuring chemical elements content in the nano-gram range of mass. Sensibility of modern X-ray methods applying the total external reflection effect and X-ray optical arrangement with a secondary target allows registration of fluorescent signal from so small quantities of substance $[1,2]$. However, the quantitative measuring the chemical element trace impurities is complicated by an absence of mass State Standards (SS) for this range. A commonly used way to prepare the standards for trace impurities is dilution of SS solutions. But the mixtures are usually inhomogeneous, and because of segregation are applicable only in fresh state, i.e. their useful life time as SS is limited; additionally, the preparation of the test samples demands a lot of time.
For the test sample preparation, various concentration techniques are used [3]: adsorption, drying, etc, which are directed to obtain the impurity mass enough for measuring with prescribed accuracy. Of great importance for such measurements is the choice of a substrate on (or in) which the preparation is contained, because it is this that specifies the background level, consequently, the mass threshold of detectability. Moreover, the adsorption coefficient variations, or insufficient adhesion of the preparation to the substrate lead to decreasing slope of the "signal-impurity mass" plot, and to rising scattering of the calibration function. Besides, the correct mass of impurity in the standards can be rarely measured by an independent method.

Stable nano-layers of metals on substrates can be obtained by magnetron scattering method using the deposition technology of X-ray mirrors [4, 6, 7]. These objects are stable for several years, and they can be 
applied as standard samples ("nanoweights") for nano-impurity analysis. The mass of such a super-smooth film on the substrate is determined by positions and intensities of interferential oscillations of $\mathrm{X}$-ray reflection coefficient $[4,5]$. These oscillations are observed experimentally beginning from $1 \mathrm{~nm}$ film thickness [5] and can serve for the substance mass independent determination by the film thickness (d) and density $(\rho)$. Actually, such measurements are possible with good accuracy for films with thickness higher than $5 \mathrm{~nm}$, where more than three orders of oscillations are observed, so as the accuracy of $\rho \cdot d$ value determination is not worse than $3-5 \%$.

The aim of the present work was preparation and investigation of high-stable standards of mass in the range from 1 to 1000 nanogram.

\section{Sample preparation and attestation methods}

Objects of studying were mass high-stable standards such as various thickness cobalt films deposited onto silicon substrates. The mass of cobalt was regulated both by the film thickness and the sample area.

Cobalt films were prepared by dc-magnetron sputtering in argon atmosphere under $0.2 \mathrm{~Pa}$ pressure. As a target, a cobalt $(99.5 \%)$ disc of $100 \mathrm{~mm}$ diameter was used. The single-crystalline Si (100) target with thickness $0.46 \mathrm{~mm}$ and surface roughness heights $\leq 0.2 \mathrm{~nm}$ was multiply exposed over the target; the constant exposure time and the fixed position over the target center were set. The constant velocity of the substrate motion was provided by a step motor connected with the substrate holder. A deposition rate and exposure time were chosen in such way as to obtain $\sim 20 \mathrm{~nm}$ metal film after 500 cycles of the deposition. Every sample was covered by an amorphous carbon $2 \mathrm{~nm}$ layer to avoid oxidation and to strengthen the sample surface.

The prepared mass samples were investigated by X-ray fluorescent analysis (XRF) using energy-dispersive spectrometer SPRUT-K (AO Ukrrentgen, Ukraine) with $\mathrm{Si}(\mathrm{Li}) \mathrm{X}-100$ detector (Amptek, USA) in the arrangement with $\mathrm{Ge}$ secondary target. An $\mathrm{X}$-ray tube BS-22 with shooting-through type $\mathrm{Ag}$ anode was applied. The arrangement aperture is $8 \cdot 10^{-6}$ (tube anode - irradiator, irradiator - sample, sample - detector). The tube regime: $U=35 \mathrm{kV}, I=250 \mu \mathrm{m}$, and exposure time $300 \mathrm{~s}$. The same method was

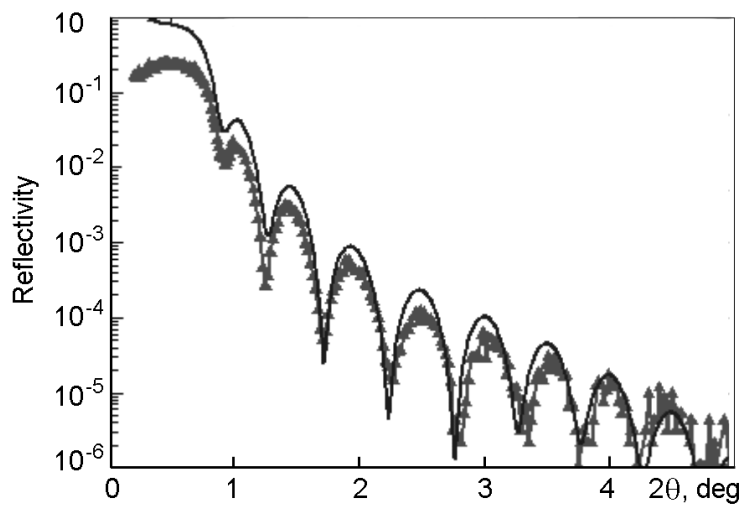

Fig. 1. Experimental (--) and calculated (-) reflectivity curves for $16.8 \mathrm{~nm}$ thickness Co film obtained after 500 deposition cycles and coated by a $2.2 \mathrm{~nm}$ protection carbon layer.

used for determination of the sample irradiated area. A square of $2 \mathrm{~mm}$ on side was cut out of usual paper and placed into the sample-holder instead of a sample. The irradiated area was determined by the variation of $\mathrm{Ca}-\mathrm{K} \alpha$ fluorescence line intensity on moving the paper relative to the sampleholder in vertical and horizontal directions with $1 \mathrm{~mm}$ step.

The homogeneity of the film was set by the sample position in the holder. The sample position was controlled using an inbuilt camera recorder with accuracy not worse than $\pm 0.2 \mathrm{~mm}$ by each coordinate. The sample high homogeneity allowed reducing the surface area by cutting to obtain mass standards less than $50 \mathrm{ng}$.

Determination of $\rho \cdot d$ value for the samples was carried out using three independent approaches. The first one allowed determination of Co layer thickness and density independently on each other by positions and intensities of X-ray reflectivity oscillations $[4,5]$. The $\mathrm{X}$-ray reflectivity angle dependence was measured using small-angle X-ray reflection method with DRON-3M diffractometer in $\mathrm{Ca}-\mathrm{K} \alpha$ radiation $(\lambda=0.15406 \mathrm{~nm})$. The reflection spectrum was modeled using X-ray Calc program by calculating the $\mathrm{X}$-ray reflectivity according to Fresnel formulas. Visual fitting of calculated and experimental spectra allowed determination of Co layer thickness and density. In Fig. 1 experimental and calculated X-ray reflectivity curves are shown for Co film of $16.8 \mathrm{~nm}$ thickness obtained for 500 deposition cycles.

Cobalt mass for the thinner films was calculated using a formula: 


$$
M_{n}=\frac{H_{500}}{500} \cdot \rho_{\mathrm{Co}} \cdot n \cdot S_{n},
$$

where $H_{500}$ is experimentally determined Co thickness after 500 cycles of deposition; $\rho_{\text {Co }}$ is experimentally determined cobalt density; $n$ is the number of deposition cycles; $S_{n}$ is the area of $n$-th sample.

The minimum thickness of the deposited film corresponded to seven cycles of deposition, and with $S_{n}=0.28 \mathrm{~cm}^{2}$ area it provided cobalt mass $53 \mathrm{ng}$ (according to Eq.(1)). For preparation of less mass standards, the sample with minimum thickness film was cut using diamond knife into rectangles with areas $0.03,0.04$, and $0.09 \mathrm{~cm}^{2}$.

The second approach consisted in determination of $\rho \cdot d$ value by XRF method by the film signal (Co-K $\alpha$ ) intensity [8]:

$$
\rho \cdot d=\left(\frac{\mu_{\mathrm{Co}}^{\mathrm{Ge}}}{\sin \varphi}+\frac{\mu_{\mathrm{Co}}^{\mathrm{Co}}}{\sin \psi}\right)^{-1} \cdot \ln \left(1-\frac{I_{\rho d}^{\mathrm{Co}}}{I_{d=\infty}^{\mathrm{Co}}}\right),
$$

where $\mu_{\text {Ce }}^{\text {Ge }}$ and $\mu_{\text {Coo }}$ are mass coefficients for cobalt absorption of the secondary target line $\mathrm{Ge}-\mathrm{K} \alpha$ and the analytical line Co-K $\alpha$ of the film, respectively; $\varphi$ is an incident angle of the secondary target radiation onto the sample; $\psi$ is the exit angle of fluorescent radiation recorded by detector; $I_{\rho d}^{\mathrm{Co}}$ is $\mathrm{Co}-\mathrm{K} \alpha$ analytical line intensity at $d \neq \infty ; I_{d=\infty}^{\mathrm{Co}}$ is the same line intensity for the sample with "infinite" thickness.

And at last, the third approach consists in determination of $\rho \cdot d$ value by film absorption of the substrate $\mathrm{Si}-\mathrm{K} \alpha$ fluorescent signal [8]:

$$
\rho \cdot d=\left(\frac{\mu_{\mathrm{Co}}^{\mathrm{Ge}}}{\sin \varphi}+\frac{\mu_{\mathrm{Co}}^{\mathrm{Si}}}{\sin \psi}\right)^{-1} \cdot \ln \left(\frac{I_{d=0}^{\mathrm{Si}}}{I_{\rho d}^{\mathrm{Si}}}\right),
$$

where $\mu_{\mathrm{C}} \mathrm{S}$ is cobalt mass coefficient of absorption of the substrate analytical line $\mathrm{Si}-\mathrm{K} \alpha ; I_{\rho d}^{\mathrm{Si}}$ is intensity of the substrate $\mathrm{Si}-\mathrm{K} \alpha$ analytical line taking into account the partial absorption of the radiation by the film; $I_{d=0}^{S i}$ is the intensity of the same line in the absence of the film.

\section{Results and discussion}

The results of the sample attestation are shown in Fig. 2. For the sample of $16.8 \mathrm{~nm}$ thickness, the parameter $\rho \cdot d$ determined by

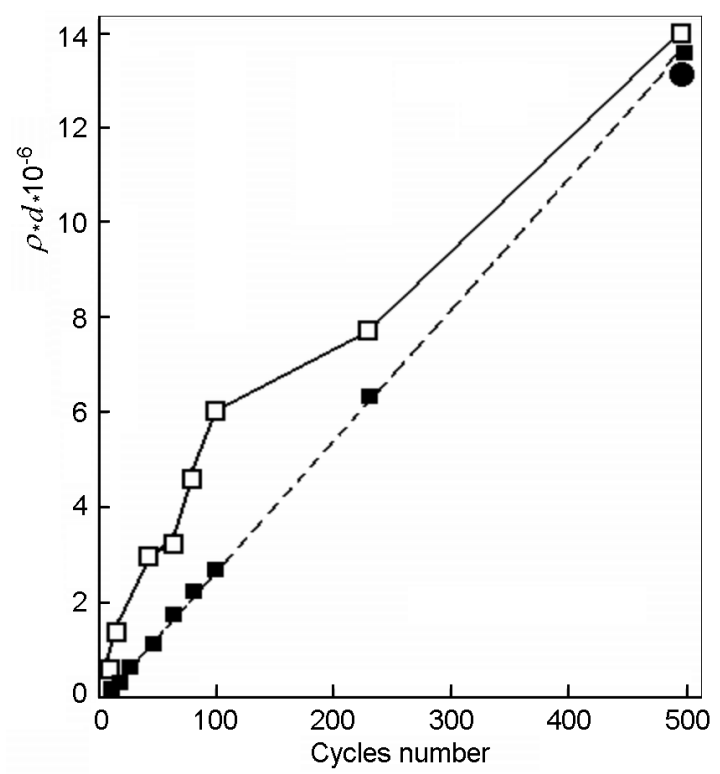

Fig. 2. Variation of $\rho \cdot d\left(\mathrm{~g} / \mathrm{cm}^{2} \cdot 10^{-6}\right)$ parameter depending on the number of deposition cycles for the sample attestation by three independent methods: $(\bullet)$ by positions and intensities of X-ray reflectivity oscillations; ( $\mathbf{\square})$ by film fluorescence radiation intensity (Co$\mathrm{K} \alpha$ line); ( $\square$ ) by substrate fluorescence radiation intensity (Si-K $\alpha$ line).

positions and intensities of $\mathrm{X}$-ray reflectivity oscillations was $\rho \cdot d=13.44 \cdot 10^{-6} \mathrm{~g} / \mathrm{cm}^{2}$. The two other methods gave the similar values for the same sample: $13.87 \cdot 10^{-6} \mathrm{~g} / \mathrm{cm}^{2}$ - by the intensity of film fluorescent radiation; and $14.04 \cdot 10^{-6} \mathrm{~g} / \mathrm{cm}^{2}-$ by cobalt film absorption of the substrate fluorescent radiation. Thus, the relative inaccuracy of the $\rho \cdot d$ determination does not exceed $2 \%$. As the cycle number decreases, the $\rho \cdot d$ value calculated by Eq.(2) drops linearly that is explained by a linear dependence of fluorescent radiation intensity on chemical element mass, cobalt in our case. The plot linearity indicates the strict constancy of the mass deposition rate, even in the cycle number range $n=1 \div 10$, that corresponds to mass less than $10 \mathrm{ng}$. The third approach gives higher values $\rho \cdot d$ than the two previous. At that, the dependence is obviously non-linear: drastic increase observed for small thicknesses loses its rate with cycle number increase and at $n=500$ the curve practically coincides with the two others. Probably, this behavior is connected with a failure in strict planarity of the film external boundary in the beginning stage of growth [5] thereupon the taken model of 


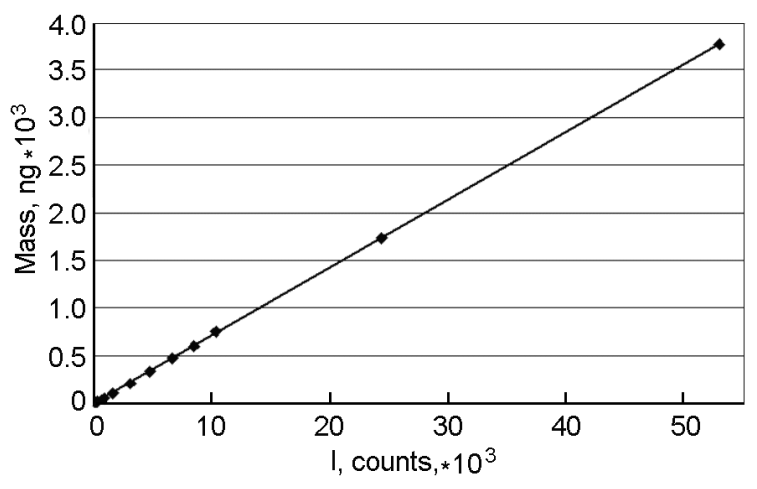

Fig. 3. The calibration function for determination of substance mass in the range from $5 \mathrm{ng}$ to $3800 \mathrm{ng}$.

substrate radiation absorption by the flat film becomes inadequate to the object. This is explained by non-homogeneity of the coating obtained under low number of deposition cycles where areas uncoated by Co film remain on the substrate. As a result, a portion of fluorescent radiation is absorbed by the coating, while the rest gets into the detector without any hindrance. As the coated area increases, more and more of the substrate area is screened by the cobalt film, and the rate of the dependence increase lowers until the whole substrate becomes coated by the film.

It is necessary to note that the first certification method as well does not take into consideration the presence of the uncoated areas on the substrate as in the case of very thin samples. The model used for calculation assumes the film thickness homogeneity over whole substrate surface. As a result under calculation of thicknesses less than $50 \mathrm{~nm}$, the chemical element mass and volume are overestimated. From our point of view the most reliable results in the range of small thicknesses gives the second approach, as it is less sensitive to the coating inhomogeneity. In Fig. 3 a calibration function built by the results of measuring the film Co-K $\alpha$ fluorescence intensity is shown. The mass of cobalt was calculated by Eq.(1). Numerical values of $\mathrm{Co}-\mathrm{K} \alpha$ line intensities are given in Table.

The mass threshold of detectability was determined for $i$-th sample as $m_{\min }=$ $3 m_{i} \sqrt{I_{B i}} / I_{C i}$, where $I_{B i}$ and $I_{C i}$ are integral intensities of background and analytical signals, respectively, and $m_{i}$ is cobalt mass in $i$-th sample. The applied method standard deviation $\bar{S}^{2}$ determined from the calibration function scattering was $8 \mathrm{ng}$. This al-

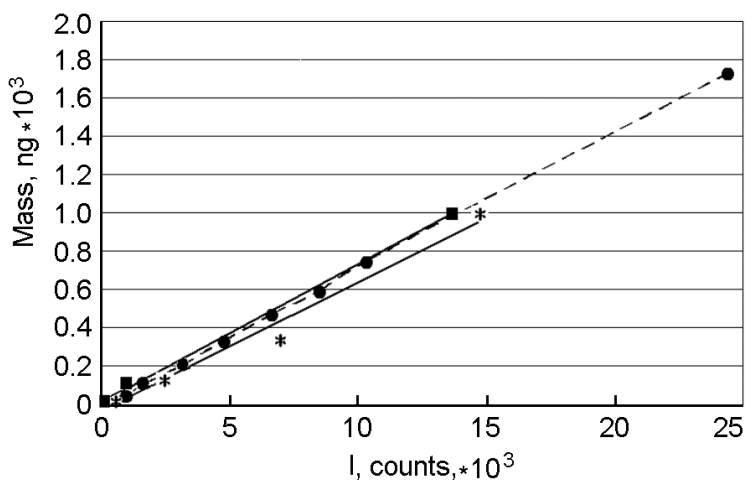

Fig. 4. Calibration functions plotted by results of measurements of magnetron Co films deposited onto Si substrates $(\bullet)$, and ones plotted for water solution SSs with gelatin fixing $(*)$ and without any fixing ( $\mathbf{(})$.

lows certifying mass values in the range from 1 to $17 \mathrm{ng}$ with accuracy not worse than $1 \mathrm{ng}$ which corresponds to the threshold of detectability, and in the range from 17 to $3800 \mathrm{ng}$ - with accuracy not worse than $8 \mathrm{ng}$.

Comparison with water solution standards. As it was mentioned above, a generally used method for preparation of the trace impurity standards is dilution of SS water solutions. Analysis of detectability thresholds for the trace impurities in such SS are discussed in detail in [9]. In the framework of the present work, the object of studying was a water solution SS PM-24 (Fe, Co, Ni, Cu), background - $\mathrm{HNO}_{3}, \mathrm{MCO}$ 0244:2001 (GSO 4146). Using dilution of the solution by water redistillate, the standard mixtures were obtained with $\mathrm{Fe}, \mathrm{Co}, \mathrm{Ni}$, and $\mathrm{Cu}$ chemical element contents in the concentration range from 3.3 to $330 \mathrm{ng} / \mathrm{cm}^{3}$. After that, $1 \mathrm{~cm}^{3}$ of the solution was dried on 3525 ULTRALENE (SPEX SamplePrep) ultrathin films. The experiment was carried out both without any fixation of the residual on the film, and with fixation by addition of gelatin into the solution. Comparison of calibration functions plotted by the results of the present work with ones from [9] is given in Fig. 4. The good correlation of the results indicates that application of high-stable Co films as mass standards is similar to application of water solution SS. Additionally, it is worth to note that the cobalt films as SS have a number of substantial advantages. First, under drying water solutions it is difficult to achieve the sample homogeneity. As the liquid is evaporated, the solution is gradually concentrated, so the material is non-ho- 
I.F.Mikhailov et al. / High-stable standard samples of...

Table. Co nano-film parameters and results of testing by fluorescent Co-K $\alpha$ radiation intensity

\begin{tabular}{|c|c|c|c|c|c||}
\hline $\begin{array}{c}\text { Number of } \\
\text { cycles, } n\end{array}$ & Thickness, nm & Area, $\mathrm{cm}^{2}$ & Mass, ng & $\begin{array}{c}\text { Co-Ko intensity, } \\
\text { counts }\end{array}$ & $\begin{array}{c}\text { Threshold of } \\
\text { detectability, ng }\end{array}$ \\
\hline 7 & 0.24 & 0.03 & 5.6198 & 0.94 & 224 \\
7 & 0.24 & 0.04 & 7.5 & 340 & 1.11 \\
7 & 0.24 & 0.09 & 16.9 & 929 & 1.64 \\
7 & 0.24 & 0.28 & 52.7 & 1668 & 2.09 \\
14 & 0.47 & 0.28 & 105.4 & 3147 & 2.13 \\
27 & 0.91 & 0.28 & 203.2 & 4777 & 2.29 \\
44 & 1.48 & 0.28 & 331.2 & 6723 & 2.33 \\
63 & 2.12 & 0.28 & 474.2 & 8542 & 2.30 \\
79 & 2.65 & 0.28 & 594.6 & 10394 & 2.39 \\
100 & 3.36 & 0.28 & 752.6 & 24457 & 2.34 \\
230 & 7.73 & 0.28 & 1731.1 & 53092 & 2.34 \\
500 & 16.80 & 0.28 & 3763.2 & & \\
\hline
\end{tabular}

mogeneously distributed over the substrate. Second, keeping the open ampoules with SS water solutions is not recommended by manufacturer, while keeping the prepared samples (after drying) is practically impossible. At the same time, the solid film samples can be damaged only in mechanical way. And, at last, the most important advantage, from our point of view, is the possibility to attest the high-stable cobalt films by several independent methods, while the water solution SS's cannot be attested at all in the range under our consideration.

The high-stable film standards are applicable for measurements not only cobalt but other elements, although as the atomic number decreases $Z<27$, the measurement accuracy will be lowered. To recalculate the calibration function shown in Fig. 3 it is enough to introduce a coefficient $K$, which for $i$ element is calculated as follows [8]:

$$
K_{i}=\frac{\frac{S_{q i}-1}{S_{q i}} \cdot \mu_{i}^{\mathrm{Ge}} \cdot \omega_{q i} \cdot \rho_{i}}{\frac{S_{q s}-1}{S_{q s}} \cdot \mu_{i}^{\mathrm{Ge}} \cdot \omega_{q s} \cdot \rho_{s}},
$$

where $S_{q i}$ and $S_{q s}$ are values of absorption jump for $i$-th element and the standard, respectively; $\mu_{i}^{\mathrm{Ge}}$ and $\mu_{s}^{\mathrm{Ge}}$ are mass attenuation factors of the secondary target $\mathrm{Ge}-$ $\mathrm{K} \alpha$ radiation by $i$-th element and the standard, respectively; $\omega_{q i}$ and $\omega_{q s}$ are fluorescence yields of $i$-th element and the standard; $\rho_{i}$ and $\rho_{s}$ are densities of $i$-th element and the standard, respectively.

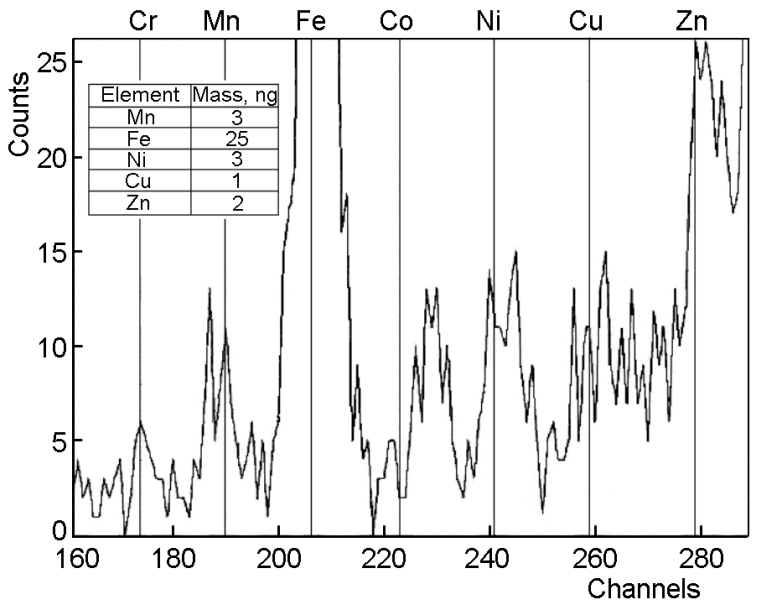

Fig. 5. The fragment of mineral water fluorescence spectrum with results of calculations of micro-element masses: $\mathrm{Mn}, \mathrm{Fe}, \mathrm{Ni}, \mathrm{Cu}$, and $\mathrm{Zn}$. The sample preparation: drying $0.5 \mathrm{~cm}^{3}$ of liquid on ultrathin films 3525 ULTRALENE (SPEX SamplePrep). Tube regime: $U=35 \mathrm{kV}, I=250 \mu \mathrm{A}$, exposure $600 \mathrm{~s}$.

Using the developed standards we succeeded in quantitative determination of $\mathrm{Mn}$, $\mathrm{Fe}, \mathrm{Ni}, \mathrm{Cu}$ and $\mathrm{Zn}$ in the mass range from $1 \mathrm{ng}$ to $15 \mathrm{ng}$ by the spectrum of mineral water (Fig. 5). The results are completely correspond to the data obtained using the water solution standards PM-24.

\section{Conclusions}

The super-smooth metal layers prepared by magnetron deposition onto single-crystalline substrates are homogeneous, stable and allow attestation by several independent methods. Therefore these can be applied as 
mass standards in the range from $1 \mathrm{ng}$ to $3800 \mathrm{ng}$. The measurement accuracy in the range from 1 to $17 \mathrm{ng}$ is not worse than $1 \mathrm{ng}$, and in the range from 17 to $3800 \mathrm{ng}$ - not worse than $8 \mathrm{ng}$.

Comparison of calibration functions plotted by the measurements of water solution SSs and the ones for high-stable Co films showed good correspondence of the results at indisputable advantages of the film standards.

\section{References}

1. M.G.Vasin, Yu.V.Ignatyev, A.E.Lakhtikov et al., X-Ray Spectrometry, 36, 270 (2007).

2. I.F.Mikhailov, A.A.Baturin, A.I.Mikhailov, S.S.Borisova, Functional Materials, 18, 150 (2011).

3. J.Injuk., R.Van Grieken, A.Blank, Handbook of Practical X-Ray Fluorescence Analysis. Ch. 6:
Specimen Preparation, Springer Verlag, Berlin (2006).

4. E.Spiller, Soft X-ray Optics, SPIE, Bellingham, Washington (1994).

5. I.F.Mikhailov, S.S.Borisova, L.P.Fomina et al., Proc.SPIE "X-Ray Optics and Surface Science", 2453, 186 (1995).

6. Ye.A.Bugaev., A.Yu.Devizenko., E.N.Zubarev, V.V.Kondratenko, Functional Materials, 14, 573 (2007).

7. I.A.Artyukhov, A.V.Vinogradov, Ye.A.Bugayev et al., Zhurnal Eksperimentalnoy $i$ Teoreticheskoy Fiziki, 136, 1009 (2009).

8. V.P.Afonin, N.I.Komyak, V.P.Nikolayev, R.I.Plotnikov, X-ray Fluorescent Analysis, ed. by N.F.Losev, Nauka, Novosibirsk (1991).

9. I.F.Mikhailov, A.A.Baturin, A.I.Mikhailov, Ye.A.Bugayev, Pribory $i$ Tekhnika Eksperimenta, 1, 95 (2013).

\title{
Високостабільні стандартні зразки маси у нанограмному діапазоні
}

\author{
І.Ф. Михайлов, О.А. Батурин, С.А. Бугаєв, \\ А.І. Михайлов, С.С. Борисова
}

\begin{abstract}
Досліджено високостабільні еталони мас, отримані методом магнетронного осадження надгладких шарів металів на монокристалічні підкладки. Тонкоплівкові еталони відповідають вимогам, які висуваються до державних стандартних зразків: вони стабільні у часі і дозволяють проведення атестації кількома незалежними методами. Забезпечено точність вимірювань маси у діапазоні від 1 до 17 нг не гірше 1 нг, а від 17 до 3800 нг не гірше 8 нг.
\end{abstract}

